\title{
Impact of atlas-CT-based bone anatomy compensation on MR-based attenuation correction for brain PET imaging in a time-of- flight PET/MRI system: A direct comparison to a patient-CT-based approach
}

\author{
Jaewon Yang ${ }^{1 *}$, Yiqiang Jian², Michel Tohme ${ }^{2}$, Spencer Behr ${ }^{1}$, Daniel Vigneron ${ }^{1}$, Sharmila Majumdar ${ }^{1}$, \\ Youngho Seo'
}

From PSMR 2015: 4th Conference on PET/MR and SPECT/MR

La Biodola, Isola d'Elba, Italy. 17-21 May 2015

${ }^{1}$ University of California, San Francisco, USA
An atlas-CT-based bone-anatomy compensation for MR-based attenuation correction (MRAC) in brain PET/MRI imaging is a current standard. However, the impact of an anatomical difference has not been clinically evaluated. Thus, we aim to evaluate the impact of the anatomical dissimilarity on MRAC. Whole-body FDG-PET/CT followed by PET/MRI were performed for twelve patients in an integrated TOF PET/MRI system. The MRAC utilized an atlas-CT (MRAC-atlas) as well as a patient-specific-CT (MRAC patient) to produce AC maps (pseudo-CT). Instead of using atlas-CT, the MRAC-patient approach derived pseudo-CT from patient-specific-CT aligned to MR. For quantitative evaluation, CTAC was considered as gold standard for $\mathrm{AC}$, and PET mean activity concentration values were measured and compared in eight $10 \mathrm{ml}$ volumes-of-interest (VOI). PET activity concentration with MRAC, compared to CTAC, were systematically underestimated on average by $0.63 \pm 0.34 \mathrm{kBq} / \mathrm{ml}(4.0 \pm 2.2 \%)$ and $0.22 \pm 0.21 \mathrm{kBq} / \mathrm{ml}(1.4 \pm 1.5 \%)$ for the MRAC-atlas and the MRAC-patient, respectively: using the MRAC atlas, the error was increased to $0.41 \pm 0.25 \mathrm{kBq} / \mathrm{ml}(2.6 \pm 1.8 \%)$ on average $(\mathrm{p} \approx 0)$. However, the error increase was patient-dependent (highest: $5.7 \%$ vs. lowest: $0.3 \%$ ) and VOI dependent (highest $3.1 \%$ vs. lowest: $1.9 \%$ ). For the first time, the atlas-CT based MRAC was compared to the patient-specific-CT-based MRAC for brain PET imaging in an integrated TOF PET/ MRI system. Overall, the MRAC-atlas achieves quantification accuracy similar to CTAC with a small but measurable difference of $5 \%$ in values, which is $2.6 \%$ higher than the error of the MRAC-patient.

\section{Authors' details}

'University of California, San Francisco, USA. ${ }^{2}$ GE Healthcare, USA.

\section{SpringerOpen ${ }^{\circ}$}

(C) 2015 Yang et al; licensee Springer. This is an Open Access article distributed under the terms of the Creative Commons Attribution License (http://creativecommons.org/licenses/by/4.0), which permits unrestricted use, distribution, and reproduction in any medium, provided the original work is properly cited. 
Cite this article as: Yang et al: Impact of atlas-CT-based bone anatomy compensation on MR-based attenuation correction for brain PET imaging in a time-of-flight PET/MRI system: A direct comparison to a patient-CT-based approach. EJNMMI Physics 2015 2(Suppl 1):A68.

Submit your manuscript to a SpringerOpen ${ }^{\odot}$ journal and benefit from:

- Convenient online submission

- Rigorous peer review

- Immediate publication on acceptance

- Open access: articles freely available online

- High visibility within the field

- Retaining the copyright to your article

Submit your next manuscript at $\boldsymbol{\nabla}$ springeropen.com 